\title{
LUDWIG'S ANGINA INFECTION IN A CHILD: A CAUSE FOR CONCERN
}

Ngeow W.C. Ludwig's angina infection in a child: a cause for concern. Annal Dent Univ Malaya 1999; 6: 31 32.

\section{ABSTRACT}

Ludwig's angina is a rare type of facial infection usually reported in adults. This paper presents a case of Ludwig's angina infection occurring in a 3 year-old Malay boy. The dentists must be able to detect such presentation early. Hospitalisation for monitoring of airway is essential.

Key words: Ludwig's angina, caries, airway, child

\section{INTRODUCTION}

Dental infections can present as abscesses, sinus tracts or cellulitis involving the submental, submandibular, submasseteric or deep neck spaces. Ludwig's angina is one of the dental infections that continues to occur despite widespread use of antibiotics.

Ludwig's angina is a rapidly progressive cellulitis that involves bilateral sublingual, submandibular and submental spaces. It is characterised as a brawny swelling in the submandibular region and elevation of the tongue and floor of the mouth. Airway obstruction may occur through posterior and superior displacement of oral structures of the pharynx (1).

Pre-existing acute dental infections in the form of abscesses, post-extraction sepsis and pericoronitis are the most common causes. Other causes include infected fractures of the mandible, penetrating injuries of the neck and mouth and suppurative sialadenitis (2). Before the introduction of antibiotic therapy, the mortality rate often exceeded $50 \%$ (3). With the advent of antibiotics, mortality rate has decreased dramatically to less than $10 \%$ (4).

Ludwig's angina has been reported to occur more commonly in adults than children (1,3-9). A rare case Ludwig's angina had been reported to occur in a 12-dayold baby boy (6). This paper reports of a Ludwig's angina infection in a 3-year-old Malay child.

\section{CASE REPORT}

A medically fit 3-year-old Malay boy was brought to the Department of Oral and Maxillofacial Surgery of the University of Malaya with a complaint of persistent fever and swelling over the submandibular and sublingual regions(Figure 1). A colleague at the same unit saw him two weeks before because of toothache and a small swelling over the mandible. His problem was deemed common and he was prescribed $250 \mathrm{mg}$ acetaminophen (paracetamol) in syrup form to be taken four times a day. An appointment was made to have the carious teeth removed under general anaesthesia as he was very uncooperative and unwilling to have his teeth examined. The colleague thought it was best for him to have all the carious teeth removed in order to save him from any further visit to the dentist as managing him would be very difficult.

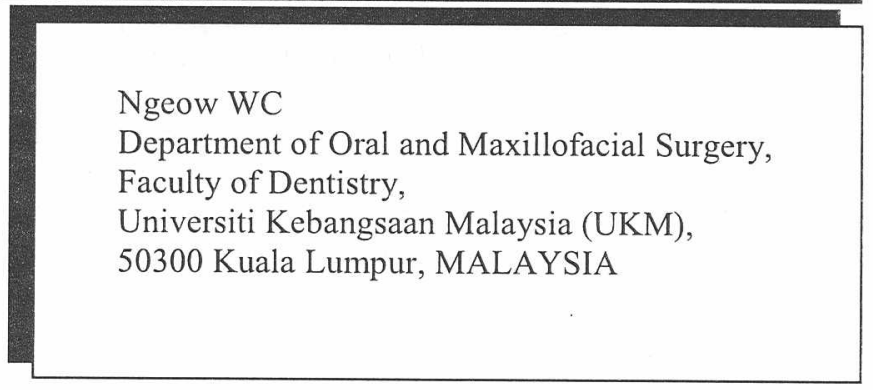

The child was in distress and was very uncooperative. His oral temperature was $39^{\circ} \mathrm{C}$. He was unwilling to undergo proper examination. His mouth opening was limited and all his visible teeth seemed to be carious. His tongue was partially elevated. The bilateral swelling on his submandibular and sublingual region was brawny red and "woody" firm, giving the impression of Ludwig's angina infection. No radiographs could be taken, as the child was uncooperative.

He was immediately admitted to the Paediatric Ward and prescribed intravenous antibiotics of Unasyn $650 \mathrm{mg}$ tds, Cloxacillin $250 \mathrm{mg}$ qid and Metronidazole 80 $\mathrm{mg}$ tds. He was also prescribed syrup acetaminophen (paracetamol) $200 \mathrm{mg}$ qid to control his fever and pain. A consultation with the anaesthetist on-call was arranged to ensure that the swelling was not threatening his airway. $\mathrm{He}$ was monitored closely every 15 minutes to make sure he did not develop difficulty in breathing. Emergency tracheotomy may be required if his airway become embarrassed.

The provisional diagnosis made based on the child's clinical presentation was Ludwig's angina infection due to carious deciduous teeth, most probably originating from 74 and 75 .

Figure 1. Side view of the child shows a large swelling over the submandibular, sublingual and submental region. The child was uncooperative, therefore no other views of the swelling could be taken

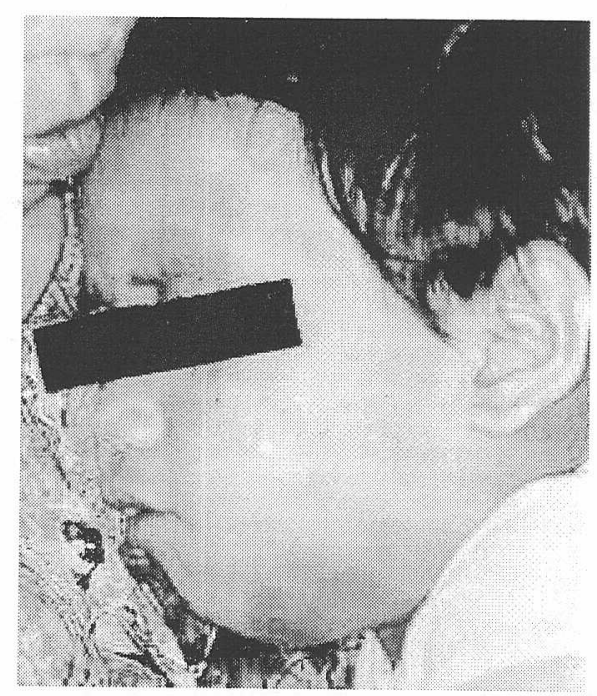


On the second day of admission, the abscess ruptured and the pus collected was sent for culture and sensitivity test. Scanty growth of streptococcus species was reported. Though there was some drainage of pus, the swelling remained large. Thus, on the fourth day of admission, the carious teeth were removed under general anaesthesia when he did not seem to pose any general anaesthetic risk. All his mandibular teeth were removed. Almost all his maxillary teeth were removed except for 55 , 64 and 65. Extraoral incision and drainage following the readily available tract were done at the same time. Recovery was uneventful.

\section{DISCUSSION}

Ludwig's angina is an aggressive rapidly spreading cellulitis that affects the submandibular, sublingual and submental spaces bilaterally $(1,2)$. The formation of this extensive brawny swelling because of the spreading cellulitis will cause elevation and posterior displacement of the tongue with consequent airway obstruction (2). The main objective in the management of Ludwig's angina is the maintenance of the airway and the control of infections with appropriate antibiotics, as described above. In this case the choice of antibiotics prescribed was determined by the paediatrician-on-call.

Ludwig's angina has rarely been reported to occur in association with caries in children $(7,8,9)$. The clinical presentation of this case is similar to those seen in cases of Ludwig's angina among adults. Among the feature seen was a brawny "woody" firm swelling spreading bilaterally to involve the sublingual, submental and submandibular spaces. The patient's mouth opening was limited and his tongue was partially elevated.

It seems that the progressive dental infection from the carious 74 and 75 might have eventually resulted in this Ludwig's angina infection. It is harder to explain the presentation in this child when compared to those seen in adults, as most Ludwig's anginas in adults are more commonly associated with the second and third permanent mandibular molars. These teeth may have their apices located below the mylohyoid ridges resulting in a close relationship with the submandibular space. It is thought the same relationship may have existed between the carious 74 and 75 and the submandibular space in this case. Progressive odontogenic infections from the apices of the carious deciduous molar teeth might have spread and resulted in perforation of the lingual plate of the mandible. Thus the submandibular spaces became directly affected, followed subsequently by other adjacent tissue spaces.

The management of the patient's airway is of prime concern. Creating an artificial airway is imperative when the airway is compromised $(2,3)$. The removal of the cause of infection is the next step of treatment, once the airway patency is ensured. In general the causative tooth/teeth needs to be removed.

Although uncommon, the general practitioner must be alert when presented with a child with dental infection as it may progress to become Ludwig's angina. Ludwig's angina infection in a child could be life threatening and must be managed as an emergency case.

\section{ACKNOWLEDGMENT}

The author wishes to acknowledge the permission from the late Dr. Kherman Shah Abdul Ghani for allowing him to report this case.

\section{REFERENCES}

1. Iwu CO. Ludwig's angina: report of seven cases and review of current concepts in management. Br J Oral Maxillofac Surg. 1990;28:189-93.

2. Tuffin JR. Ludwig's angina: an unusual sequel to endodontic therapy. Inter Endodont J. 1989;22:142-7.

3. Williams AC, Guralnick WC. The diagnosis and treatment of Ludwig's angina. N Engl J Med. 1943;228:445-50.

4. Hought RT, Fitzgerald BE, Latta JE, Zallen RD. Ludwig'g angina: report of two cases and review of the literature from 1945 to January 1979. J Oral Surg. 1980;38:849-55.

5. Sethi DS, Stanley RE. Deep neck abscesses changing trends: J Laryngol Otol. 1994;108:138-43.

6. Steinhauer PF. Ludwig's angina: report of a case in a 12-day-old boy. J Oral Surg. 1967;25:251-4.

7. Gross SJ, Nieburg PI. Ludwig angina in childhood. Am J Dis Child. 1977;131:291-2.

8. Barkin RM, Boris SC, Elghammer RM, Todd JK. Ludwig angina in children. J Pediatr 1975;87:583-5.

9. Schuman NJ, Owens BM. Ludwig's angina following dental treatment for a five-year-old male patient: report of a case. J Clin Pediatr Dent. 1992;16:263-5. 